•研究报告・

\title{
海南岛翼手目物种多样性现状与分布预测
}

\author{
胡宜峰 ${ }^{1}$ 余文华 ${ }^{1}$ 岳 阳 $^{1}$ 黄正澜懿 李玉春 $^{2}$ 吴 毅 $1^{*}$ \\ 1 (广州大学生命科学学院, 广州 510006) \\ 2 (山东大学(威海)海洋学院, 山东威海 264209)
}

\begin{abstract}
摘要: 海南岛位于我国南部, 地处热带北缘, 其独特的岛屿气候环境孕育了丰富的生物资源, 为我国生物多样性 热点地区之一。为探究岛内的翼手目物种多样性状况, 本研究组使用雾网、蝙蝠坚琴网等工具, 于2002年至2016 年先后对海南岛进行了15次翼手目多样性调查, 并根据其外形与头骨特征及系统发育学方法进行标本鉴定。共获 取了1,025号标本，隶属5科15属31种，其中2016年12月21日在海南琼中捕获的艾氏管鼻蝠(Murina eleryi)为海南岛 蝙蝠分布新记录。结合前人调查及发表结果统计, 岛内共有翼手类 8 科 20 属 41 种。同时基于本调查采集位点和前人 调查位置信息(共计363个位点), 结合WorldClim 32种气候数据, 运用最大熵模型(MaxEnt)对海南岛翼手目物种的 分布进行预测, 结果显示五指山、吊罗山、鸭哥岭、尖峰岭及海口火山口国家地质公园等地为翼手目物种多样性 较丰富的区域, 而三亚、澄迈、屯昌、临高、琼海等地翼手目物种多样性较低。本研究结果为海南岛翼手目资源 分布及多样性状况提供了基础资料, 也为岛内后续开展翼手目资源保护管理、蝙蝠疾病防控等提供了重要的参考 依据。
\end{abstract}

关键词：翼手目; 海南岛; 艾氏管鼻蝠; 物种多样性; 最大熵(MaxEnt)模型

\section{Species diversity and potential distribution of Chiroptera on Hainan Island, China}

Yifeng $\mathrm{Hu}^{1}$, Wenhua $\mathrm{Yu}^{1}$, Yang Yue ${ }^{1}$, Zhenglanyi Huang ${ }^{1}$, Yuchun $\mathrm{Li}^{2}$, Yi Wu${ }^{1 *}$

1 School of Life Sciences, Guangzhou University, Guangzhou 510006

2 Marine College, Shandong University, Weihai, Shandong 264209

\begin{abstract}
Hainan Island is a key biodiversity hotspot in China with a unique ecosystem and climate. In order to explore the species diversity of Chiroptera on the island, 15 bat surveys were carried out in the area between 2002 and 2016. During these surveys, mist nets, harp traps and other tools were deployed. Captured specimens were identified according to their external form, skull features and phylogenetic description. In total, 1,025 specimens from 5 families, 15 genera and 31 species were recorded and collected. On December 21, 2016, two small Murina bats were captured in a harp-trap in a forest at Chaocan Village, Qiongzhong City, Hainan Province. Based on external, cranio-dental characteristics and phylogenetic evidence, the bats were identified as Murina eleryi. This is the first record of the species on Hainan Island. Based from our survey result and literature review, Chiroptera of Hainan Island consists of a total of 8 families 20 genera and 41 species. The potential distribution area of bats on Hainan Island was mapped using a maximum entropy (MaxEnt) model incorporating 363 local records, derived from our records and the literature. High diversity was predicted for Wuzhi Mountain, Diaoluo Mountain, Yinggeling, Jianfengling and Huoshankou National Geopark whereas the low diversity was predicted for Sanya, Chengmai, Tunchang, Lingao, Qionghai areas. Overall, baseline data for Chiroptera distribution, and resource status was assessed by the current study, which is useful for disease prevention, control, resource conservation and management on Hainan Island.
\end{abstract}

Key words: Chiroptera; Hainan Island; Murina eleryi; species diversity; maximum entropy (MaxEnt) 
翼手目是哺乳动物中仅次于啮齿目动物的第 二大类群(Simmons, 2005), 我国总计8科135种(蒋 志刚等, 2017)。翼手目种类作为唯一一类具有飞行 能力的特殊哺乳动物, 习性独特, 生活环境隐蔽, 其基础本底资料相对匮乏。

海南岛为我国第二大岛 $\left(18^{\circ} 9^{\prime}-20^{\circ} 11^{\prime} \mathrm{N}\right.$, $108^{\circ} 36^{\prime}-111^{\circ} 4^{\prime}$ E), 处于印度尼西亚一马来西亚热 带区的北缘，为我国典型热带气候区域之一，年平 均气温高, 降水量大(高素华等, 1988)。海南岛中南 部由五指山、鹦哥岭、吊罗山、尖峰岭等山脉组成, 北部及岛屿四周则以丘陵、平原和滨海沙滩逐级过 渡, 动物的种类、种群数量、地理分布在不同区域 也有所不同(徐龙辉等, 1983; 高素华等, 1988; 颜家 安, 2008; 车秀芬等, 2014), 是我国生物多样性最高 的地区之一，也是世界生物多样性研究和保护的热 点地区(李玉春等, 2005; 史海涛等, 2011), 具有极 高的研究价值。岛内翼手目的早期主要研究包括: 徐龙辉等(1983)在海南岛鸟兽调查中对翼手目的种 类和分布进行了初步报道; 吴毅等(2003)对吊罗山 保护区内翼手类物种多样性进行了初步研究; 李玉 春等(2006a)对马鞍岭火山口保护区翼手目进行了 调查报道; 朱斌良等(2008)对海南岛翼手目多样性 状况进行了初步探讨; 李德伟等(2010)对海南岛翼 手目的分布格局进行了研究。上述工作主要集中在 部分地区且以洞穴型蝙蝠为主，尚缺乏对全岛、以 森林型蝙蝠为重点的专项研究。

本研究组从2002年起，持续关注海南岛翼手目 多样性状况，除继续对洞穴型蝙蝠的研究外，使用 蝙蝠坚琴网重点对岛内森林型蝙蝠进行研究, 通过 15 次的野外调查, 共采集蝙蝠标本 1,025 号, 隶属5 科15属31种。还结合前人文献资料对岛内翼手目物 种多样性与分布状况进行梳理, 运用最大熵物种分 布模型(MaxEnt)(Phillips et al, 2006)对该类群岛内 潜在分布区进行预测, 进一步明确了翼手类在岛内 的分布现状, 为后续该类群针对性调查提供借鉴与 指引, 还能够为该类群日后的保护管理、深入研究 及以蝙蝠为媒介的疾病防控提供基础资料。

\section{材料与方法}

\section{1 标本的采集及物种鉴定}

课题组在2002至2016年间进行了15次海南岛 翼手目资源调查, 调查范围覆盖海南岛内的主要保
护区。使用手网、雾网和坚琴网等工具进行采集捕 捉, 参照哺乳动物测量标准(杨奇森等, 2007), 对采 集到的标本进行外部形态与头骨测量，并进行物种 鉴定(刘少英和吴毅, 2019)。外部形态测量指标包括: 前臂长(forearm length)、尾长(tail length)、后足长 (hindfoot length)、胫骨长(tibia length)、耳长(ear length); 头骨测量指标包括: 颅全长(greatest length of skull)、枕犬长(condylo-canine length)、歡宽 (zygomatic width)、眶间宽(interorbital of width)、脑 乑高(braincase height)、腭长(palate length)、上齿列 长 (upper canine-third molar length)、上犬齿宽 (rostrum width across upper canines)、上兒齿宽 (width across third upper molars)、上犬齿前臼齿长 (upper canine-premolar length)、下犬齿前臼齿长 (lower canine-premolar length)、下齿列长(lower canine-third molar length)、下领长 (mandibular length)、下领高(mandibular height)。

在经初步形态鉴定后，对部分存疑的标本进一 步使用系统发育学方法辅助物种鉴定：剪取约 $20 \mathrm{mg}$ 肌肉组织, 利用TaKaRa MiniBEST Universal Genomic DNA Extraction Kit (TAKARA, 大连)提取 总DNA; 使用引物(COI-f: 5'-ACA GCC TAA TAC CTA CTC GGC CAT T-3'和 COI-r: 5'-AGG CTC GGG TGT CTA CGT CCA-3')扩增线粒体COI基因 (约641 bp); 测序工作由上海美吉生物医药科技有 限公司完成; 将测序结果在 GENEIOUS 5.4 (Drummond et al, 2011)中进行目测校对与拼接，联 合 GenBank数据库中 467 条管鼻蝠线粒体 COI基因 序列使用 Muscle (Edgar，2004) 进行排序，使用 ModelTest确定最优化核苷酸替换模型(Posada \& Crandall, 1998), 在MEGA 6.0软件中采用邻接法 (neighbour-joining method)构建系统发育树(Saitou \& Nei，1987), 自展(bootstraps) 500次估计其系统发 生树的节点支持度。

\section{2 海南岛蝙蝠多样性状况汇总分析及潜在空间} 分布的预测

为更好地了解翼手目在海南岛的分布状况，对 课题组采集的标本及海南岛现有的翼手目历史分 布记录进行梳理汇总(寿振黄等, 1966; 徐龙辉等, 1983；史海涛, 2001；王应祥, 2003; 江海声等, 2006; 李玉春等，2006a，b; 余文华等，2008; 张礼标等， 2008; 朱斌良等, 2008; 朱光剑等, 2008a, b; 李德伟 
等, 2010; Wu et al, 2010, 2012; 蒋志刚等, 2015; 胡 宜峰等, 2018; Yu et al, 2018), 依据《中国动物地理》 (张荣祖, 1999) 和《中国脊椎动物红色名录》(蒋志 刚等, 2016)对物种区系及濒危等级进行划分。

本研究汇总课题组实地调查及前人记录的GPS 信息位点共363个, 运用MaxEnt模型(Phillips et al, 2006)重建该类群在岛内的适生区域。将世界气候数 据库(Worldclim version 1.3, http://www.worldclim.org; Hijmans et al, 2005)中的32个精度为 $30 "\left(\right.$ 约 $\left.1 \mathrm{~km}^{2}\right)$ 的 海拔、气候与降雨因子汇同分布点导入MaxEnt软件 以重建类群适生分布区域, 使用刀切法(Jackknife test)评估温度、降雨量及海拔等因子的重要性(附录 1), 随机检验百分比(random test percentage)设置为 $25 \%$, 重复设置为 10 次, 重复类别为Subsample, 采 用 ROC 曲线(受试者工作特征曲线)下面积 (area under the receiving operator curve, AUC)对预测精度 进行评价。

\section{2 结果}

\section{1 海南岛蝙蝠物种多样性状况}

本研究在2002年至2016年间共捕获蝙蝠标本 1,025 只, 经鉴定, 隶属5科 15 属 31 种。结合前人资料, 迄今海南岛记录翼手目 8 科 20 属41种, 占中国翼手 目种类的 $30.4 \%$ 。其中蝙蝠科种类最多, 达 24 种, 占 海南岛翼手目种类的 $58.5 \%$; 蹄蝠科种类次之, 共5 种，占 $12.2 \%$; 菊头蝠科 4 种，占 $9.8 \%$; 长翼蝠科 3 种， 占 $7.3 \%$; 狐蝠科 2 种，占 $4.9 \%$; 鞘尾蝠科、犬吻蝠 科、假吸血蝠科各 1 种, 各占 $2.4 \%$ 。在物种分布型方 面：东洋型种类 27 种，占 $65.9 \%$; 季风型 3 种，占 7.3\%; 南中国型6种，占14.6\%; 古北界成分中古北 型2种，占 $4.9 \%$; 其他不易归类的3种，占 $7.3 \%$ (附 录2)。

在物种鉴定中发现, 2016 年 12 月 21 日在琼中 县朝参村人工林 $\left(19^{\circ} 03^{\prime} 50^{\prime \prime} \mathrm{N}, 109^{\circ} 45^{\prime} 42^{\prime \prime} \mathrm{E}\right.$, 海拔 $423 \mathrm{~m}$ ) 使用坚琴网采集的 2 只管鼻蝠 (Male: GZHU16448; Female: GZHU16452), 根据其外部形 态、头骨特征及系统发育学证据, 被鉴定为艾氏管 鼻蝠(Murina eleryi; 图 1, 附录 3), 为海南岛翼手目 分布新记录。

41种蝙蝠中, 彩蝠(Kerivoula picta) 被列为濒危 (EN) 级, 犬蝠 (Cynopterus sphinx)、大菊头蝠 (Rhinolophus luctus)、普氏蹄蝠(Hipposideros pratti)、
中华鼠耳蝠(Myotis chinensis)、大足鼠耳蝠(M. pilosus)、高㧫鼠耳蝠(M. siligorensis)、小伏翼(Pipistrellus tenuis)、灰伏翼(Hypsugo pulveratus)、南蝠 (Ia io)、褐扁颅蝠(Tylonycteris robustula)、圆耳管鼻蝠 (Murina cyclotis)、艾氏管鼻蝠、毛翼管鼻蝠(Harpiocephalus harpia)、暗褐彩蝠(Kerivoula furva)、亚洲 长翼蝠(Miniopterus fuliginosus)、几内亚长翼蝠( $M$. magnater)、南长翼蝠( $M$. pusillus)共17种被列为近危 (NT)等级，印度假吸血蝠(Megaderma lyra)和无尾 蹄蝠(Coelops frithii)被列为易危(VU)等级, 数据缺 乏(DD)的有1种，即哈氏管鼻蝠(Murina harrisoni), 其余20种均为无危(LC)(附录2)。

不同蝙蝠在岛内的采集和记录数量以及分布 状况显示：中菊头蝠(Rhinolophus affinis)、小菊头蝠 (R. pusillus)、中华菊头蝠 ( $R$. sinicus)、中蹄蝠 (Hipposideros larvatus)和小黄蝠(Scotophilus kuhlii) 等5种在岛内有较大的种群数量且分布区域较广; 棕果蝠(Rousettus leschenaultii)、犬蝠、黑髯墓蝠 (Taphozous melanopogon)、大菊头蝠、大蹄蝠 (Hipposideros armiger)、小蹄蝠(H. pomona)、无尾 蹄蝠、华南水鼠耳蝠(Myotis laniger)、大足鼠耳蝠、 东亚伏翼 (Pipistrellus abramus)、印度伏翼 (P. coromandra)、普通伏翼(P. pipistrellus)、灰伏翼、 褐扁秒蝠、斑蝠(Scotomanes ornatus)、大黄蝠 (Scotophilus heathi)、亚洲长翼蝠、几内亚长翼蝠和 南长翼蝠等19种在岛内有一定的种群数量或有较 广的分布区域; 而皱唇犬吻蝠(Chaerephon plicata)、 中华鼠耳蝠、大卫鼠耳蝠(Myotis davidii)、霍氏鼠耳 蝠(M. horsfieldii)、高乑鼠耳蝠、锡兰伏翼 (Pipistrellus ceylonicus)、南蝠、中华山蝠(Nyctalus pla$n c y i) 、$ 圆耳管鼻蝠、艾氏管鼻蝠、哈氏管鼻蝠、毛 翼管鼻蝠、彩蝠、暗褐彩蝠等14种在岛内的种群数 量少且分布范围较小; 另有小伏翼、普氏蹄蝠、印 度假吸血蝠3种只有文献记录, 但无具体采集地点 (附录2)。

不同市级行政区中，陵水分布的翼手目种类最 多，达27种，其次分别是琼中(22种)、海口 (16种)等, 而临高(2种)、屯昌(2种)、澄迈(1种)、三亚(1种)等 区域则种类较少(图2)。

\section{2 海南岛蝙蝠的适生分布区预测}

MaxEnt模型结果显示, 10次Subsample的平均 训练集AUC值为 0.73 。Jackknife检验结果提示：海 


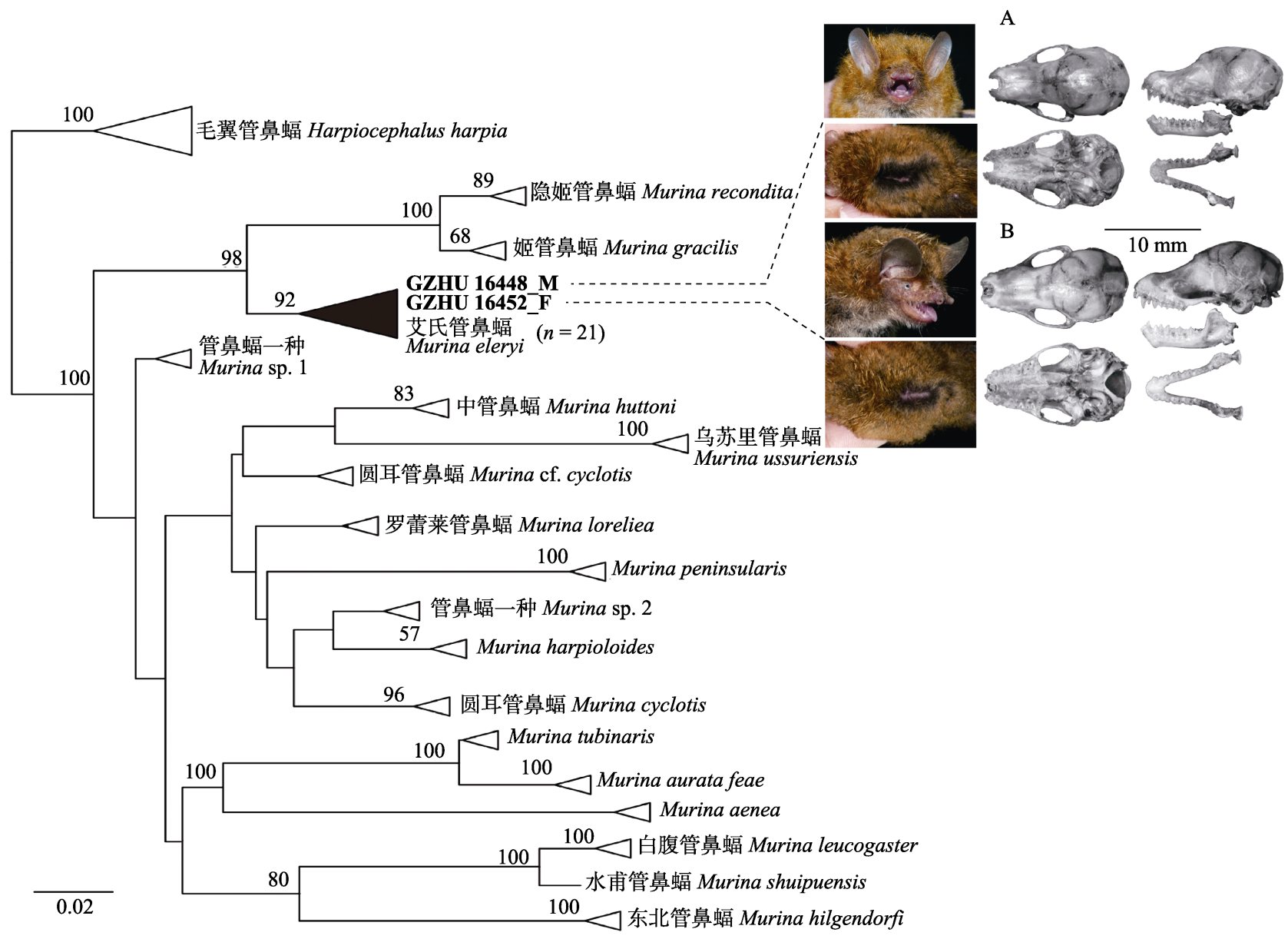

图1 基于641 bp COI序列运用邻接法构建的管鼻蝠系统发生树及艾氏管鼻蝠外形和头骨(A：雄性; B: 雌性)

Fig. 1 Neighbour-joining tree of Murina based on 641 bp COI gene, the external, skull and mandibule characters of Murina eleryi (A, Male; B, Female)

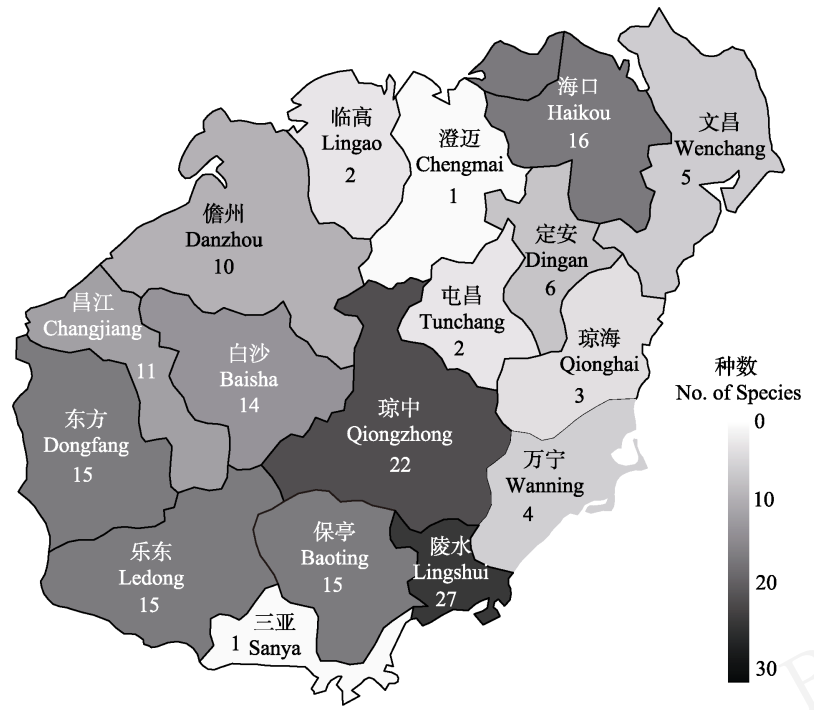

图2 海南岛各地区翼手目资源调查情况。颜色越深其蝙蝠 生物多样性越高, 数字代表物种数。

Fig. 2 The distribution of bat species in different city of Hainan Island. The darker colors show areas with higher bat biodiversity, figures represent the number of species.
拔、最暖季度平均温度、最热月份最高温度、年平 均温度为影响蝙蝠类群分布的主要气候因子(图3)。 此外, MaxEnt模型预测海南岛蝙蝠的高适生区主要 集中在五指山、吊罗山、鹦哥岭、尖峰岭及火山口 等地区，而三亚、澄迈、屯昌、琼海等则为低适生 区(图4)。

\section{3 讨论}

艾氏管鼻蝠作为典型的树栖蝙蝠，活动隐秘， 难捕捉，标本量少，对该物种的报道和描述相对缺 之。其国内已知分布区包括广西和贵州(Francis \& Eger, 2012)、湖南 (刘志霄等, 2014)、广东 (徐忠鲜等, 2014), 本次在海南采集到艾氏管鼻蝠扩大了该种 类在国内的分布区，为该种类在我国最南缘的分布 记录。该记录也使海南岛内管鼻蝠种类由原有的 2 种增至3种，翼手目种数增至41种。鉴于海南岛作 


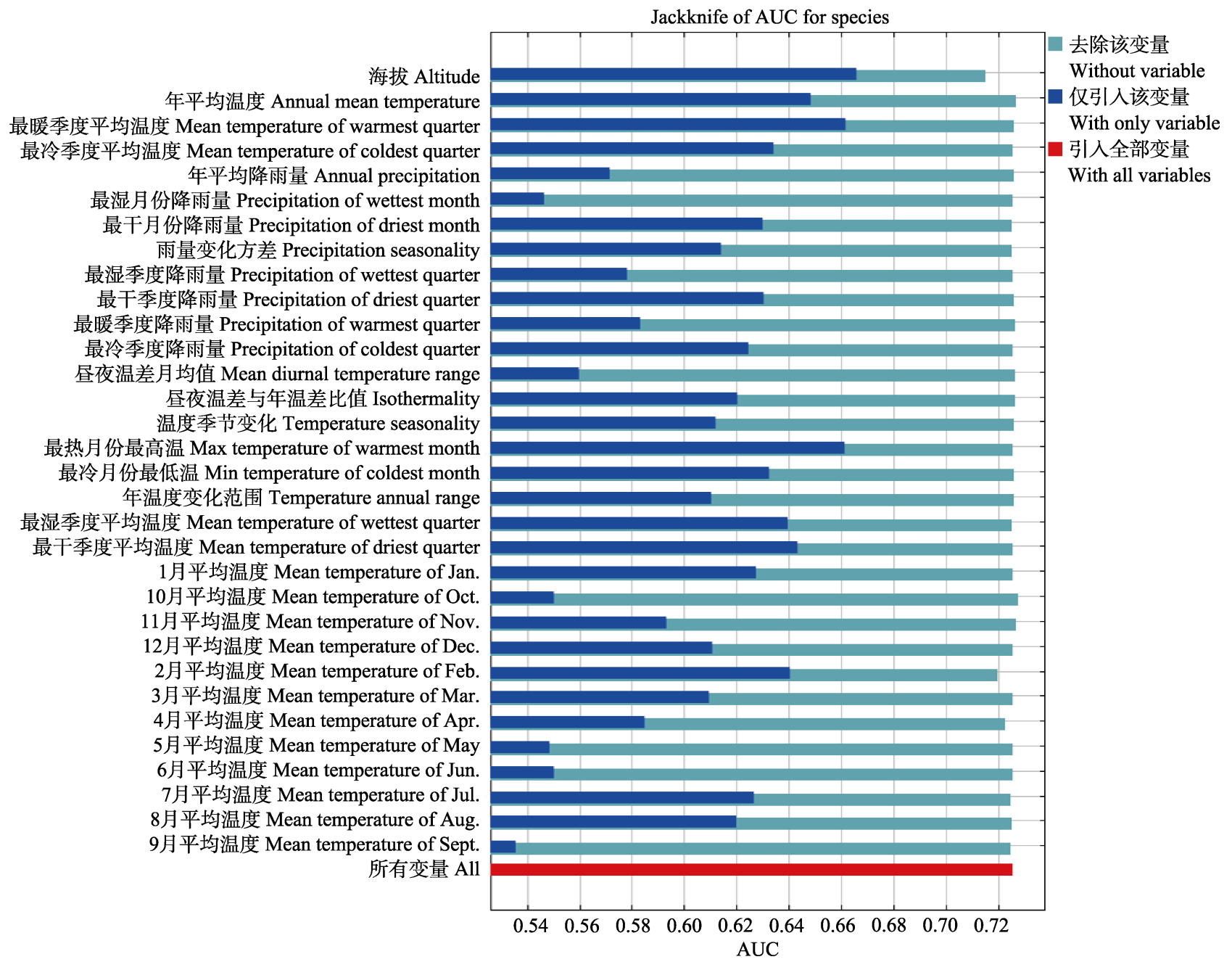

图3 环境变量重要性的刀切法检验

Fig. 3 Results of Jackknife test of environment variable importance

为我国重要的生物多样性热点区之一, 且翼手目物 种在低纬度区域具有更高丰富度的规律(Buckley et $\mathrm{al}, 2010)$, 我们认为现阶段岛内的翼手目多样性仍 有被低估的可能。

与其他调查组相比, 本研究组自2008年起, 通 过使用坚琴网, 进一步发掘海南岛内树栖型蝙蝠多 样性状况, 采集到树栖型蝙蝠共计18种, 占海南岛 翼手目种类的 $43.9 \%$; 发现了褐扁乑蝠(余文华等, 2008)、泰坦尼亚彩蝠(Kerivoula titania) (Wu et al, 2012)、毛翼管鼻蝠(胡宜峰等, 2018)以及艾氏管鼻 蝠(本研究)共4个树栖蝙蝠新记录。其中2012年采集 的泰坦尼亚彩蝠和文献中记载的哈氏彩蝠 $(K$. hardwickii)经过Yu等(2018)厘定后确定为暗褐彩蝠。 在调查过程中我们也发现, 部分国内较常见的种类 如东亚伏翼仅在乐东、陵水和海口有分布记录, 印
度假吸血蝠、普氏蹄蝠和小伏翼作为早期文献记录 种类在近15年的调查中均未发现(附录2), 这可能是 因为: (1)调查力度不够; (2)部分区域由于自然资源 的开发, 导致蝙蝠栖息地被破坏。因此有必要对这些 分布记录进行实地考证以核实其种群现状。

最大熵模型已成功且广泛地运用在植物群落 和一些物种的适生区预测中(Phillips et al, 2006; 崔 绍朋等, 2018; 武晓宇等, 2018), 本研究MaxEnt模 型模拟结果显示, 翼手目多样性高的区域主要集中 于海南岛的中南部以及北部区域，而这些区域则主 要围绕着五指山、尖峰岭、吊罗山以及火山口等植 被较好且人类活动较少的区域。对蝙蝠在海南岛内 分布影响较大的环境因子是: 海拔、最暖季度平均 温度、最热月份最高温度、年平均温度, 该结果与 李玉春等(2005)在基于全国尺度条件下提出的影响 




图4 蝙蝠在海南岛的适生区。物种存在的概率为 $0-1$, 暖色 为物种存在概率高的区域, 最高为红色, 最低为深蓝色。

Fig. 4 Suitable habitat distribution of bats in Hainan Island. The species existing probability range from 0 to 1 . Warmer colors show areas with higher predicted probability, red is the highest, dark blue is the lowest.

翼手目分布规律的主要影响因子(如年平均温度、大 于零度日数、1月平均温度、年降雨量)存在一定差 异, 但我们认为该差异主要源于分析尺度与使用方 法不同所致, 而且二者共同提示年平均温度是影响 蝙蝠分布的重要因素之一。

蝙蝠是生态系统中的重要成员之一, 具有举足 轻重的生态作用(Williams-Guillén et al, 2008; Maine \& Boyles, 2015), 其在岛内的资源状况与本底信息 的明确是相关保护工作开展的前提与基础。同时, 大量研究指出蝙蝠为多种致病病毒的天然宿主, 如 埃博拉病毒、SARS病毒、马尔堡病毒以及狂犬病 毒等(Calisher et al, 2006; Daszak, 2010; Wong et al, 2010; Olival et al, 2017), 故其本底信息的明确无疑 有着重要的疾控与防治意义。与实地调查不同, 通 过MaxEnt模型可快速整合分布记录与生态学数据 完成类群的潜在分布区预测, 但模型的稳定性与准 确性受样本数量和样本地理空间分布两方面的制 约(Manel et al, 2001), 本研究中的部分文献记载的 GPS数据缺失导致采集位点只能粗略定位, 这对蝙 蝠适生区预测产生的影响难以评估。另一方面, 本 研究仅选取了常规使用的海拔、降雨量、温度等气 候因子, 而植被情况、洞穴分布情况以及人类活动 等因子由于数据不全或缺乏而无法纳入, 已有文献 指出部分生态因子对蝙蝠分布具有重要影响, 如洞
穴位置、理化特征、人为干扰程度等(Russo et al, 2002; 张成菊和吴毅, 2006; Johnson et al, 2009), 故 后续的研究中应适当补充相关数据以进一步提高 模型的准确性, 为该类群的本底调查、类群的生态 保护及疾病防控提供指引。

\section{参考文献}

Buckley LB, Davies TJ, Ackerly DD, Kraft NJB, Harrison SP, Anacker BL, Cornell HV, Damschen EI, Grytnes JA, Hawkins BA, McCain CM, Stephens PR, Wiens JJ (2010) Phylogeny, niche conservatism and the latitudinal diversity gradient in mammals. Proceedings of the Royal Society B: Biological Sciences, 277, 2131-2138.

Calisher CH, Childs JE, Field HE, Holmes KV, Schountz T (2006) Bats: Important reservoir hosts of emerging viruses. Clinical Microbiology Reviews, 19, 531-545.

Che XF, Zhang JH, Huang HJ, Liu SJ, Zhang MJ (2014) Climate regionalization in Hainan Island. Chinese Journal of Tropical Agriculture, 34(6), 60-65. (in Chinese with English abstract) [车秀芬, 张京红, 黄海静, 刘少军, 张明洁 (2014) 海南岛气候区划研究. 热带农业科学, 34(6), 60-65.]

Cui SP, Luo X, Li CW, Hu HJ, Jiang ZG (2018) Predicting the potential distribution of white-lipped deer using the MaxEnt model. Biodiversity Science, 26, 171-176. (in Chinese with English abstract) [崔绍朋, 罗晓, 李春旺, 胡慧建, 蒋志刚 (2018) 基于MaxEnt模型预测白唇鹿的潜在分布区. 生物 多样性, 26, 171-176.]

Daszak P (2010) Bats, in black and white. Science, 329, 634-635.

Drummond MJ, McCarthy JJ, Sinha M, Spratt HM, Volpi E, Esser KA, Rasmussen BB (2011) Aging and microRNA expression in human skeletal muscle: A microarray and bioinformatics analysis. Physiological Genomics, 43, 595-603.

Edgar RC (2004) MUSCLE: Multiple sequence alignment with high accuracy and high throughput. Nucleic Acids Research, 32, 1792-1797.

Francis CM, Eger JL (2012) A review of tube-nosed bats (Murina) from Laos with a description of two new species. Acta Chiropterologica, 14, 15-38.

Gao SH, Huang ZM, Zhang TQ, Lin X (1988) Climate of Hainan Island. China Meteorological Press, Beijing. (in Chinese) [高素华, 黄增明, 张统钦, 林熙 (1988) 海南岛 气候. 气象出版社, 北京.]

Hijmans RJ, Cameron SE, Parra JL, Jones PG, Jarvis A (2005) Very high interpolated climate surfaces for global land areas. International Journal of Climatology, 25, 1965-1978.

Hu YF, Li F, Wu Y, Li YC, Yu WH (2018) New record of Harpiocephalus harpia in Hainan Province. Journal of Zhejiang Forestry Science and Technology, 38(3), 85-88. 
(in Chinese with English abstract) [胡宜峰, 黎舫, 吴毅, 李玉春, 余文华 (2018) 海南省蝙蝠新记录——毛翼管 鼻蝠. 浙江林业科技, 38(3), 85-88.]

Jiang HS, Song XJ, Liao WB, Li TH, Wu Y, Jin JH, Zou FS, Dong SY, Yi ZS, Zhou GY, Song B, Ke MH (2006) The Biodiversity and Its Conservation of Diaoluo Mountain, Hainan, China. Guangdong Science and Technology Press, Guangzhou. (in Chinese) [江海声, 宋晓军, 廖文波, 李泰 辉, 吴毅, 金建华, 邹发生, 董仕勇, 易祖盛, 周光益, 宋 斌, 柯铭辉 (2006) 海南吊罗山生物多样性及其保护. 广 东科技出版社, 广州.]

Jiang ZG, Jiang JP, Wang YZ, Zhang E, Zhang YY, Li LL, Xie F, Cai B, Cao L, Zheng GM, Dong L, Zhang ZW, Ding P, Luo ZH, Ding CQ, Ma ZJ, Tang SH, Cao WX, Li CW, Hu HJ, Ma Y, Wu Y, Wang YX, Zhou KY, Liu SY, Chen YY, Li JT, Feng ZJ, Wang Y, Wang B, Li C, Song XL, Cai L, Zang CX, Zeng Y, Meng ZB, Fang HX, Ping XG (2016) Red List of China's Vertebrates. Biodiversity Science, 24, 500-551. (in Chinese and in English) [蒋志刚, 江建平, 王 跃招, 张鹗, 张雁云, 李立立, 谢锋, 蔡波, 曹亮, 郑光 美, 董路, 张正旺, 丁平, 罗振华, 丁长青, 马志军, 汤宋 华, 曹文宣, 李春旺, 胡慧建, 马勇, 吴毅, 王应祥, 周开 亚, 刘少英, 陈跃英, 李家堂, 冯祚建, 王燕, 王斌, 李 成, 宋雪琳, 蔡蕾, 蔵春金金, 曾岩, 孟智斌, 方红霞, 平晓 鸽 (2016) 中国脊椎动物红色名录. 生物多样性, 24, 500-551.]

Jiang ZG, Liu SY, Wu Y, Jiang XL, Zhou KY (2017) China’s mammal diversity (2nd edition). Biodiversity Science, 24, 886-895. (in Chinese with English abstract) [蒋志刚, 刘少 英, 吴毅, 蒋学龙, 周开亚 (2017) 中国哺乳动物多样性 (第2版). 生物多样性, 25, 886-895.]

Jiang ZG, Ma Y, Wu Y, Wang YX, Zhou KY, Liu SY, Feng ZJ, Li LL (2015) China's Mammal Diversity and Geographic Distribution. Science Press, Beijing. (in Chinese with English abstract) [蒋志刚, 马勇, 吴毅, 王应祥, 周开 亚, 刘少英, 冯祚建, 李立立 (2015) 中国哺乳动物多样 性及地理分布. 科学出版社, 北京.]

Johnson JB, Edwards JW, Ford WM, Gates JE (2009) Roost tree selection by northern myotis (Myotis septentrionalis) maternity colonies following prescribed fire in a Central Appalachian Mountains hardwood forest. Forest Ecology and Management, 258, 233-242.

Li DW, Yin F, Zeng Y, Zhang Y, Zhang XW (2010) Cluster analysis on the distribution patterns of Chiroptera in Hainan Island. Journal of Biology, 27(2), 16-20. (in Chinese with English abstract) [李德伟, 尹锋, 曾玉, 张园, 张信文 (2010) 海南岛翼手类地理分布格局的聚类分析. 生物学 杂志, 27(2), 16-20.]

Li YC, Meng YH, Zhang LC, Ye Q (2005) Analysis of environmental factors on geographical distribution of Chinese Chiroptera. Acta Zoologica Sinica, 51, 413-422. (in Chinese with English abstract) [李玉春, 蒙以航, 张利存, 叶青 (2005) 中国翼手目地理分布的环境因子影响分析.
动物学报, 51, 413-422.]

Li YC, Chen Z, Long YR, Zhou F, Zhong YR (2006a) Species diversity of Chiroptera in Ma'anling volcano area, Hainan Island. Chinese Journal of Zoology, 41(3), 106-109. (in Chinese with English abstract) [李玉春, 陈忠, 龙育儒, 周 锋, 钟友仁 (2006a) 海南岛马鞍岭火山口地区翼手目物 种多样性. 动物学杂志, 41(3), 106-109.]

Li YC, Wu Y, Chen Z (2006b) A new record of Rickett's big-footed bat Myotis ricketti in Hainan Island of China. Acta Theriologica Sinica, 26, 211-212. (in Chinese with English abstract) [李玉春, 吴毅, 陈忠 (2006b) 海南岛发 现大足鼠耳蝠分布新纪录. 兽类学报, 26, 211-212.]

Liu SY, Wu Y (2019) Handbook of the Mammals of China. The Straits Publishing \& Distributing Group, Fuzhou. (in Chinese) [刘少英, 吴毅 (2019) 中国兽类图鉴. 海峡书局 出版社, 福州.]

Liu ZX, Zhang YX, Zhang JS, Zhang LB (2014) Murina eleryi discovered in Hunan Province. Chinese Journal of Zoology, 49, 132-135. (in Chinese with English abstract) [刘志霄, 张佑祥, 张劲硕, 张礼标 (2014) 湖南省发现艾氏管鼻 蝠. 动物学杂志, 49, 132-135.]

Maine JJ, Boyles JG (2015) Bats initiate vital agroecological interactions in corn. Proceedings of the National Academy of Sciences, USA, 112, 12438-12443.

Manel S, Williams HC, Ormerod SJ (2001) Evaluating presence-absence models in ecology: The need to account for prevalence. Journal of Applied Ecology, 38, 921-931.

Olival KJ, Hosseini PR, Zambrana-Torrelio C, Ross N, Bogich TL, Daszak P (2017) Host and viral traits predict zoonotic spillover from mammals. Nature, 546, 646-650.

Phillips SJ, Anderson RP, Schapire RE (2006) Maximum entropy modeling of species geographic distributions. Ecological Modelling, 190, 231-259.

Posada D, Crandall KL (1998) ModelTest: Testing the model of DNA substitution. Bioinformatics, 14, 817-818.

Russo D, Jones G, Migliozzi A (2002) Habitat selection by the Mediterranean horseshoe bat, Rhinolophus euryale (Chiroptera: Rhinolophidae) in a rural area of southern Italy and implications for conservation. Biological Conservation, 107, 71-81.

Saitou N, Nei M (1987) The Neighbor-Joining method: A new method for reconstructing phylogenetic trees. Molecular Biology and Evolution, 4, 406-425.

Shaw TH, Wang S, Lu CK, Chang LK (1966) A survey of the mammals of Hainan Island, China. Acta Zootaxonomica Sinica, 3, 260-276. (in Chinese with English abstract) [寿振 黄, 汪松, 陆长坤, 张鑾光 (1966) 海南岛的兽类调查. 动物分类学报, 3, 260-276.]

Shi HT (2001) Retrieval of Terrestrial Vertebrates in Hainan. Hainan Publishing House, Haikou. (in Chinese) [史海涛 (2001) 海南陆栖脊椎动物检索. 海南出版社, 海口.]

Shi HT, Zhao EM, Wang LJ, Bi H, Lü SQ, Liu HN, Wang JC, Zhao H, Hong ML (2011) Amphibians and Reptiles of 
Hainan. Science Press, Beijing. (in Chinese) [史海涛, 赵尔 宓, 王力军, 毕华, 吕顺清, 刘惠宁, 汪继超, 赵惠, 洪美 玲 (2011) 海南两栖爬行动物志. 科学出版社, 北京.]

Simmons NB (2005) Order Chiroptera // Mammal Species of the World: A Taxonomic and Geographic Reference, 3rd edn. The Johns Hopkins University Press, Maryland.

Wang YX (2003) A Complete Checklist of Mammal Species and Subspecies in China: A Taxonomic and Geographic Reference. China Forestry Publishing House, Beijing. (in Chinese) [王应祥 (2003) 中国哺乳动物物种与亚种分类 名录与分布大全. 中国林业出版社, 北京.]

Williams-Guillén K, Prefecto I, Vandermeer J (2008) Bats limit insects in a neotropical agroforestry system. Science, 320, 70.

Wong S, Lau S, Woo P, Yuen KY (2010) Bats as a continuing source of emerging infections in humans. Reviews in Medical Virology, 17(2), 67-91.

Wu XY, Dong SK, Liu SL, Liu QR, Han YH, Zhang XL, Su XK, Zhao HD, Feng J (2018) Identifying priority areas for grassland endangered plant species in the Sanjiangyuan Nature Reserve based on the MaxEnt model. Biodiversity Science, 26, 138-148. (in Chinese with English abstract) [武 晓宇, 董世鬼, 刘世梁, 刘全儒, 韩雨晖, 张晓蕾, 苏旭 坤, 赵海迪, 冯憬 (2018) 基于MaxEnt模型的三江源区草 地濒危保护植物热点区识别. 生物多样性, 26, 138-148.]

Wu Y, Jiang HS, Peng HY, Li SN, Wang WY (2003) Study on the species biodiversity of mammals in Diaoluoshan Mountain. Journal of Guangzhou University (Natural Science Edition), 2, 505-511. (in Chinese with English abstract) [吴 毅, 江海声, 彭洪元, 李仕宁, 王文毅 (2003) 吊罗山保 护区哺乳动物多样性初步研究. 广州大学学报(自然科学 版), 2, 505-511.]

Wu Y, Li YC, Lin LK, Harada M, Chen Z, Motokawa M (2012) New records of Kerivoula titania (Chiroptera: Vespertilionidae) from Hainan Island and Taiwan. Mammal Study, 37, 69-72.

Wu Y, Motokawa M, Li YC, Harada M, Chen Z, Yu WH (2010) Karyotype of Harrison's tube nosed bat Murina harrisoni (Chiroptera: Vespertilionidae: Murininae) based on the second specimen recorded from Hainan Island, China. Mammal Study, 35, 277-279.

Xu LH, Liu ZH, Yu SM (1983) Birds and Beasts in Hainan Island, China. Science Press, Beijing. (in Chinese) [徐龙辉, 刘振河, 余斯绵 (1983) 海南岛的鸟兽. 科学出版社, 北 京.]

Xu ZX, Yu WH, Wu Y, Li F, Chen BC, Harada M, Motokawa M, Gong YN, Li YC (2014) Preliminary study on population genetic structure and taxonomy of Elery's tube-nosed bat (Murina eleryi). Acta Theriologica Sinica, 34, 270-277. (in Chinese with English abstract) [徐忠鲜, 余文华, 吴毅, 李锋, 陈柏承, 原田正史, 本川雅治, 龚粤宁, 李玉春 (2014) 艾氏管鼻蝠种群遗传结构初步研究及其分类探 讨. 兽类学报, 34, 270-277.]
Yan JA (2008) Study on Evolution History of Hainan Island's Ecological Environment. Science Press, Beijing. (in Chinese) [颜家安 (2008) 海南岛生态环境变迁研究. 科 学出版社, 北京.]

Yang QS, Xia L, Feng ZJ, Ma Y, Quan GQ, Wu Y (2007) A guide to the measurement of mammal skull $\mathrm{V}$, Insectivora and Chiroptera. Chinese Journal of Zoology, 42(2), 56-62. (in Chinese with English abstract) [杨奇森, 夏霖, 冯祚建, 马勇, 全国强, 吴毅 (2007) 兽类头骨测量标准V, 食虫 目、翼手目. 动物学杂志, 42(2), 56-62.]

Yu WH, Wu Y, Li YC, Jiang HS, Chen Z (2008) A new record of greater bamboo bat Tylonycteris robustula of Hainan Island. Journal of Guangzhou University (Natural Science Edition), 7, 30-33. (in Chinese with English abstract) [余文 华, 吴毅, 李玉春, 江海声, 陈忠 (2008) 海南岛发现褐 扁颅蝠(Tylonycteris robustula)分布新纪录. 广州大学学 报(自然科学版), 7, 30-33.]

Yu WH, Li F, Csorba G, Xu ZX, Wang XY, Guo WJ, Li YC, Wu Y (2018) A revision of Kerivoula hardwickii and occurrence of $K$. furva (Chiroptera: Vespertilionidae) in China. Zootaxa, 4461, 45-56.

Zhang CJ, Wu Y (2006) Habitat selection of environment, ecological function and protection of cave bat. Bulletin of Biology, 41(5), 4-6. (in Chinese) [张成菊, 吴毅 (2006) 洞 穴型蝙蝠的栖息环境选择、生态作用及保护. 生物学通 报, 41(5), 4-6.]

Zhang LB, Zhu GJ, Yu DM, Ye JP, Zhang W, Hong TY, Tan M (2008) New record of Tylonycteris robustula (Chiroptera: Vespertilionidae) from Hainan, Guizhou, and Sichuan Province. Acta Theriologica Sinica, 28, 316-320. (in Chinese with English abstract) [张礼标, 朱光剑, 于冬梅, 叶建平, 张伟, 洪体玉, 谭敏 (2008) 海南、贵州和四川 三省翼手类新纪录——褐扁颖蝠. 兽类学报, 28, 316-320.]

Zhang RZ (1999) Zoogeography of China. Science Press, Beijing. (in Chinese) [张荣祖 (1999) 中国动物地理. 科学 出版社, 北京.]

Zhu BL, Zhu GJ, Li DW, Hong TY, Zhang XW (2008) A preliminary survey on species diversity of Chiroptera in Hainan Island. Journal of Hainan Normal University (Natural Science), 21, 75-81. (in Chinese with English abstract) [朱斌良, 朱光剑, 李德伟, 洪体玉, 张信文 (2008) 海南岛翼手目物种多样性的初步调查. 海南师范 大学学报(自然科学版), 21, 75-81.]

Zhu GJ, Li DW, Ye JP, Hong TY, Zhang LB (2008a) New record of Ia io in Hainan Island, its echolocation pulses and ND1 analysis. Chinese Journal of Zoology, 43, 69-75. (in Chinese with English abstract) [朱光剑, 李德伟, 叶建平, 洪体玉, 张礼标 (2008a) 南蝠海南岛分布新纪录、回声定 位信号和ND1分析. 动物学杂志, 43, 69-75.]

Zhu GJ, Han NJ, Hong TY, Tan M, Yu DM, Zhang LB (2008b) Echolocation call, roost and ND1 sequence analysis of new record of Nyctalus plancyi (Chiroptera: Vespertilionidae) on 
Hainan Island. Zoological Research, 29, 447-451. (in Chinese with English abstract) [朱光剑, 韩乃坚, 洪体玉, 谭敏, 于冬梅, 张礼标 (2008b) 海南属种新纪录一一 华山蝠的回声定位信号、栖息地及序列分析. 动物学研
究, 29, 447-451.]

(责任编委: 蒋学龙 责任编辑: 问文杰)

\section{附录 Supplementary Material}

附录1 用于MaxEnt模型中的环境因子变量

Appendix 1 Environmental variables used in MaxEnt model

http://www.biodiversity-science.net/fileup/PDF/2018256-1.pdf

附录2 海南岛蝙蝠名录、分布及保护现状

Appendix 2 List of specimens, distribution localities and conservation status of bats in Hainan Island, China

http://www.biodiversity-science.net/fileup/PDF/2018256-2.pdf

\section{附录3 不同地区的艾氏管鼻蝠及金管鼻蝠的外形及头骨测量}

Appendix 3 The external, skull and mandibule measurements of Murina eleryi from different locations comparing with Murina aurata

http://www.biodiversity-science.net/fileup/PDF/2018256-3.pdf 
胡宜峰，余文华，岳阳，黄正澜懿，李玉春，吴毅. 海南岛翼手目物种多样性现状与分布预测. 生物多样性，2019，27 (4): 400-408.

http://www.biodiversity-science.net/CN/10.17520/biods.2018256

附录1 用于MaxEnt模型中的环境因子变量

Appendix 1 Environmental variables used in MaxEnt model

\begin{tabular}{|c|c|c|c|}
\hline 中文描述 Chinese description & 英文描述 English description & 中文描述 Chinese description & 英文描述 English description \\
\hline 海拔 & Altitude (m) & 最冷月份最低温 & Min. temperature of coldest month $\left({ }^{\circ} \mathrm{C}\right)$ \\
\hline 年平均降雨量 & Annual precipitation $(\mathrm{mm})$ & 年温度变化范围 & Temperature annual range $\left({ }^{\circ} \mathrm{C}\right)$ \\
\hline 最湿月份降雨量 & Precipitation of wettest month $(\mathrm{mm})$ & ||最湿季度平均温度 & Mean temperature of wettest quarter $\left({ }^{\circ} \mathrm{C}\right)$ \\
\hline 最干月份降雨量 & Precipitation of driest month (mm) & |最干季度平均温度 & Mean temperature of driest quarter $\left({ }^{\circ} \mathrm{C}\right)$ \\
\hline 雨量变化方差 & Precipitation seasonality & 1月平均温度 & Mean temperature of Jan. $\left({ }^{\circ} \mathrm{C}\right)$ \\
\hline 最湿季度降雨量 & Precipitation of wettest quarter (mm) & 2月平均温度 & Mean temperature of Feb. $\left({ }^{\circ} \mathrm{C}\right)$ \\
\hline 最干季度降雨量 & Precipitation of driest quarter (mm) & | 3 月平均温度 & Mean temperature of Mar. $\left({ }^{\circ} \mathrm{C}\right)$ \\
\hline 最暖季度降雨量 & Precipitation of warmest quarter $(\mathrm{mm})$ & 4月平均温度 & Mean temperature of Apr. $\left({ }^{\circ} \mathrm{C}\right)$ \\
\hline 最冷季度降雨量 & Precipitation of coldest quarter $(\mathrm{mm})$ & 5月平均温度 & Mean temperature of May $\left({ }^{\circ} \mathrm{C}\right)$ \\
\hline 年平均温度 & Annual mean temperature $\left({ }^{\circ} \mathrm{C}\right)$ & 6月平均温度 & Mean temperature of Jun. $\left({ }^{\circ} \mathrm{C}\right)$ \\
\hline 最暖季度平均温度 & Mean temperature of warmest quarter $\left({ }^{\circ} \mathrm{C}\right)$ & | 7 月平均温度 & Mean temperature of Jul. $\left({ }^{\circ} \mathrm{C}\right)$ \\
\hline 最冷季度平均温度 & Mean temperature of coldest quarter $\left({ }^{\circ} \mathrm{C}\right)$ & 8月平均温度 & Mean temperature of Aug. $\left({ }^{\circ} \mathrm{C}\right)$ \\
\hline 昼夜温差月均值 & Mean diurnal temperature range $\left({ }^{\circ} \mathrm{C}\right)$ & 9月平均温度 & Mean temperature of Sept. $\left({ }^{\circ} \mathrm{C}\right)$ \\
\hline 昼夜温差与年温差比值 & Isothermality & |10月平均温度 & Mean temperature of Oct. $\left({ }^{\circ} \mathrm{C}\right)$ \\
\hline 温度季节变化 & Temperature seasonality $\left({ }^{\circ} \mathrm{C}\right)$ & 11月平均温度 & Mean temperature of Nov. $\left({ }^{\circ} \mathrm{C}\right)$ \\
\hline 最热月份最高温 & Max. temperature of warmest month $\left({ }^{\circ} \mathrm{C}\right)$ & |12月平均温度 & Mean temperature of Dec. $\left({ }^{\circ} \mathrm{C}\right)$ \\
\hline
\end{tabular}


胡宜峰, 余文华, 岳阳, 黄正澜懿, 李玉春, 吴毅. 海南岛翼手目物种多样性现状与分布预测. 生物多样性, 2019,27 (4): 400-408.

http://www.biodiversity-science.net/CN/10.17520/biods.2018256

附录2 海南岛蝙蝠名录、分布及保护现状

Appendix 2 List of specimens, distribution localities and conservation status of bats in Hainan Island, China

\begin{tabular}{|c|c|c|c|c|}
\hline 物种 Species & $\begin{array}{l}\text { 标本数量 } \\
\text { No. of } \\
\text { specimens }\end{array}$ & $\begin{array}{ll}\text { 文献记载 } & \text { 濒危等级 } \\
\text { 数量 } & \text { IUCN } \\
\text { Recordation } & \text { categories }\end{array}$ & $\begin{array}{l}\text { 分布区系 } \\
\text { Distribution }\end{array}$ & $\begin{array}{l}\text { 采集地 } \\
\text { Location }\end{array}$ \\
\hline
\end{tabular}

\section{狐蝠科 Pteropodidae}

1. 棕果蝠

Rousettus leschenaultii

17

45

LC

$\mathrm{Wb}$

Cynopterus sphinx

\section{鞘尾蝠科 Emballonuridae}

\author{
3. 黑髯墓蝠 \\ Taphozous melanopogon
}

\section{假吸血蝠科 Megadermatidae}

4. 印度假吸血蝠

Megaderma lyra

\section{菊头蝠科 Rhinolophidae}

\author{
5. 中菊头蝠 \\ Rhinolophus affinis
}

\begin{abstract}
6. 大菊头蝠
Rhinolophus luctus
\end{abstract}

7. 小菊头蝠

Rhinolophus pusillus

8. 中华菊头蝠

Rhinolophus sinicus

\section{蹄蝠科 Hipposideridae}

9. 大蹄蝠

Hipposideros armiger
27

10

LC

Wd
白沙，保亭，海口，陵水，文昌，(昌江，万宁) [徐龙辉等, 1983; 史海涛, 2001; 王应祥, 2003; 李玉春等, 2006a; 朱光 剑等，2008a; 李德伟等，2010] Baisha，Baoting，Haikou， Lingshui, Wenchang, (Changjiang, Wanning) [Xu et al, 1983; Shi, 2001; Wang, 2003; Li et al, 2006a; Zhu et al, 2008a; Li et al, 2010]

白沙, 海口, 陵水, 琼中, (文昌, 临高, 儋州, 万宁, 定安) [徐龙辉等，1983; 史海涛，2001; 王应祥，2003; 李玉春等, 2006a; 朱斌良等, 2008; 朱光剑等, 2008a; 李德伟等, 2010] Baisha, Haikou, Lingshui, Qiongzhong, (Wenchang, Lingao, Danzhou, Wanning, Dingan) [Xu et al, 1983; Shi, 2001; Wang, 2003; Li et al, 2006a; Zhu et al, 2008; Zhu et al, 2008a; Li et al, 2010]

(昌江，东方，乐东) [徐龙辉等, 1983; 史海涛, 2001; 王应祥, 2003] (Changjiang, Dongfang, Ledong) [Xu et al, 1983; Shi, 2001; Wang, 2003]

(地点不详) [王应祥, 2003; 蒋志刚等, 2015] (Unknown) [Wang, 2003; Jiang et al, 2015]

白沙, 保亭, 海口, 乐东, 陵水, 琼中, 文昌, (儋州, 定安, 昌江，东方) [徐龙辉等，1983; 史海涛等, 2001; 王应祥, 2003; 吴毅等, 2003; 李玉春等, 2006a; 朱斌良等, 2008; 李 德伟等, 2010] Baisha, Baoting, Haikou, Ledong, Lingshui, Qiongzhong, Wenchang, (Danzhou, Dingan, Changjiang, Dongfang) [Xu et al, 1983; Shi, 2001; Wang, 2003; Wu et al, 2003; Li et al, 2006a; Zhu et al, 2008; Li et al, 2010]

白沙, 保亭, 海口, 陵水, 琼中, (儋州) [徐龙辉等, 1983; 史 海涛, 2001; 王应祥，2003; 李玉春等，2006a；朱斌良等， 2008] Baisha, Baoting, Haikou, Lingshui, Qiongzhong, (Danzhou) [Xu et al, 1983; Shi, 2001; Wang, 2003; Li et al, 2006a; Zhu et al, 2008]

保亭, 海口, 乐东, 陵水, 琼中, 文昌, (定安, 昌江, 白沙, 东方) [史海涛, 2001; 王应祥, 2003; 吴毅等, 2003; 李玉春 等, 2006a; 朱斌良等, 2008; 李德伟等, 2010] Baoting, Haikou, Ledong, Lingshui, Qiongzhong, Wenchang, (Dingan, Changjiang, Baisha, Dongfang) [Shi, 2001; Wang, 2003; Wu et al, 2003; Li et al, 2006a; Zhu et al, 2008; Li et al, 2010]

白沙, 保亭, 海口, 陵水, 琼中, (屯昌, 定安, 昌江, 东方, 乐东) [徐龙辉等, 1983; 王应祥, 2003; 吴毅等, 2003; 朱斌良 等, 2008; 李德伟等, 2010] Baisha, Baoting, Haikou, Lingshui, Qiongzhong, (Tunchang, Dingan, Changjiang, Dongfang, Ledong) [Xu et al, 1983; Wang, 2003; Wu et al, 2003; Zhu et al, 2008; Li et al, 2010]

白沙, 保亭, 陵水, 琼中, (昌江, 东方, 乐东) [徐龙辉等, 1983; 史海涛, 2001; 王应祥, 2003; 吴毅等, 2003; 朱斌良 等, 2008; 李德伟等, 2010] Baisha, Baoting, Lingshui, Qiongzhong, (Changjiang, Dongfang, Ledong) [Xu et al, 1983; Shi, 2001; Wang, 2003; Wu et al, 2003; Zhu et al, 2008; Li et al, 2010] 
胡宜峰, 余文华, 岳阳, 黄正澜懿, 李玉春, 吴毅. 海南岛翼手目物种多样性现状与分布预测. 生物多样性, 2019,27 (4): 400-408.

http://www.biodiversity-science.net/CN/10.17520/biods.2018256

\begin{tabular}{|c|c|c|c|c|c|}
\hline 物种 Species & $\begin{array}{l}\text { 标本数量 } \\
\text { No. of } \\
\text { specimens }\end{array}$ & $\begin{array}{l}\text { 文献记载 } \\
\text { 数量 } \\
\text { Recordation }\end{array}$ & $\begin{array}{l}\text { 濒危等级 } \\
\text { IUCN-cate } \\
\text { gories }\end{array}$ & $\begin{array}{l}\text { 分布区系 } \\
\text { Distribution }\end{array}$ & $\begin{array}{l}\text { 采集地 } \\
\text { Location }\end{array}$ \\
\hline $\begin{array}{l}\text { 10. 中蹄蝠 } \\
\text { Hipposideros larvatus }\end{array}$ & 43 & 182 & $\mathrm{LC}$ & $\mathrm{Wb}$ & $\begin{array}{l}\text { 保亭, 海口, 陵水, 琼中, (屯昌, 定安, 昌江, 白沙, 东方, } \\
\text { 乐东)[徐龙辉等, 1983; 史海涛, 2001; 王应祥, 2003; 李玉春 } \\
\text { 等, 2006aa; 李 德 伟 等, 2010] Baoting, Haikou, Lingshui, } \\
\text { Qiongzhong, (Tunchang, Dingan, Changjiang, Baisha, Dong- } \\
\text { fang, Ledong) [Xu et al, 1983; Shi, 2001; Wang, 2003; Li et al, } \\
\text { 2006a; Li et al, 2010] }\end{array}$ \\
\hline $\begin{array}{l}\text { 11. 小蹄蝠 } \\
\text { Hipposideros pomona }\end{array}$ & 81 & 97 & $\mathrm{LC}$ & $\mathrm{Wc}$ & $\begin{array}{l}\text { 保亭, 海口, 陵水, 琼中, (东方, 琼海, 昌江, 万宁) [寿振黄 } \\
\text { 等, 1966; 朱 斌 良 等, 2008] Baoting, Haikou, Lingshui, } \\
\text { Qiongzhong, (Dongfang, Qionghai, Changjiang, Wanning) } \\
\text { [Shaw et al, 1966; Zhu et al, 2008] }\end{array}$ \\
\hline $\begin{array}{l}\text { 12. 普氏蹄蝠 } \\
\text { Hipposideros pratti }\end{array}$ & & $\sqrt{ }$ & NT & $\mathrm{Wd}$ & $\begin{array}{l}\text { (地点不详) [王应祥, 2003; 蒋志刚等, 2015] (Unknown) } \\
\text { [Wang, 2003; Jiang et al, 2015] }\end{array}$ \\
\hline $\begin{array}{l}\text { 13. 无尾蹄蝠 } \\
\text { Coelops frithii }\end{array}$ & 5 & & VU & $\mathrm{Wb}$ & $\begin{array}{l}\text { 保亭, 琼中, (白沙, 陵水) [徐龙辉等, 1983; 王应祥, 2003; 李 } \\
\text { 德伟等, 2010] Baoting, Qiongzhong, (Baisha, Lingshui) [Xu et } \\
\text { al, 1983; Wang, 2003; Li et al, 2010] }\end{array}$ \\
\hline \multicolumn{6}{|l|}{ 犬吻蝠科 Molossidae } \\
\hline $\begin{array}{l}\text { 14. 坡唇犬吻蝠 } \\
\text { Chaerephon plicata }\end{array}$ & & $\sqrt{ }$ & $\mathrm{LC}$ & $\mathrm{We}$ & $\begin{array}{l}\text { (儋州, 东方) [徐龙辉等, 1983; 史海涛, 2001] (Danzhou, } \\
\text { Dongfang) [Xu et al, 1983; Shi, 2001] }\end{array}$ \\
\hline \multicolumn{6}{|l|}{ 蝙蝠科 Vespertilionidae } \\
\hline $\begin{array}{l}\text { 15. 中华鼠耳蝠 } \\
\text { Myotis chinensis }\end{array}$ & 1 & & NT & Uh & $\begin{array}{l}\text { 陵水 [吴毅等, 2003; 李玉春等, 2006a] Lingshui [Wu et al, } \\
\text { 2003; Li et al, 2006a] }\end{array}$ \\
\hline $\begin{array}{l}\text { 16. 大卫鼠耳蝠 } \\
\text { Myotis davidii }\end{array}$ & & $\sqrt{ }$ & $\mathrm{LC}$ & $\mathrm{E}$ & $\begin{array}{l}\text { (白沙) [徐龙辉等, 1983; 史海涛, 2001] (Baisha) [Xu et al, } \\
\text { 1983; Shi, 2001] }\end{array}$ \\
\hline $\begin{array}{l}\text { 17. 霍氏鼠耳蝠 } \\
\text { Myotis horsfieldii }\end{array}$ & 2 & & $\mathrm{LC}$ & Wa & 乐东 Ledong \\
\hline $\begin{array}{l}\text { 18. 华南水鼠耳蝠 } \\
\text { Myotis laniger }\end{array}$ & 31 & & $\mathrm{LC}$ & $\mathrm{O}_{3}$ & $\begin{array}{l}\text { 保亭, 海口, 陵水, 琼中, (儋州, 东方, 乐东) [徐龙辉等, } \\
\text { 1983; 史海涛, 2001] Baoting, Haikou, Lingshui, Qiongzhong, } \\
\text { (Danzhou, Dongfang, Ledong) [Xu et al, 1983; Shi, 2001] }\end{array}$ \\
\hline $\begin{array}{l}\text { 19. 大足鼠耳蝠 } \\
\text { Myotis pilosus }\end{array}$ & 22 & 30 & NT & Uh & $\begin{array}{l}\text { 保亭, 陵水, 琼中, (海口) [李玉春等, 2006a, b; 朱斌良等, } \\
\text { 2008; 李 德 伟 等, 2010] Baoting, Lingshui, Qiongzhong, } \\
\text { (Haikou) [Li et al, 2006a, b; Zhu et al, 2008; Li et al, 2010] }\end{array}$ \\
\hline $\begin{array}{l}\text { 20. 高顽鼠耳蝠 } \\
\text { Myotis siligorensis }\end{array}$ & & $\sqrt{ }$ & NT & $\mathrm{Sc}$ & $\begin{array}{l}\text { (儋州) [王应祥, 2003; 蒋志刚等, 2015] (Danzhou) [Wang, } \\
\text { 2003; Jiang et al, 2015] }\end{array}$ \\
\hline $\begin{array}{l}\text { 21. 东亚伏翼 } \\
\text { Pipistrellus abramus }\end{array}$ & 3 & 16 & $\mathrm{LC}$ & $\mathrm{Ea}$ & $\begin{array}{l}\text { 乐东, (陵水, 海口) [寿振黄等, 1966; 徐龙辉等, 1983; 史海 } \\
\text { 涛, 2001; 王应祥, 2003; 李玉春等, 2006a; 朱斌良等, 2008; } \\
\text { 李德伟等, 2010] Ledong, (Lingshui, Haikou) [Shaw et al, } \\
\text { 1966; Xu et al, 1983; Shi, 2001; Wang, 2003; Li et al, 2006a; } \\
\text { Zhu et al, 2008; Li et al, 2010] }\end{array}$ \\
\hline $\begin{array}{l}\text { 22. 锡兰伏翼 } \\
\text { Pipistrellus ceylonicus }\end{array}$ & 2 & 5 & $\mathrm{LC}$ & Wa & $\begin{array}{l}\text { 陵水, (东方) [寿振黄等, 1966; 徐龙辉等, 1983; 史海涛, } \\
\text { 2001; 吴毅等, 2003] Lingshui, (Dongfang) [Shaw et al, 1966; } \\
\text { Xu et al, 1983; Shi, 2001; Wu et al, 2003] }\end{array}$ \\
\hline $\begin{array}{l}\text { 23. 印度伏翼 } \\
\text { Pipistrellus coromandra }\end{array}$ & 1 & 22 & $\mathrm{LC}$ & Wc & $\begin{array}{l}\text { 琼中, (琼海, 昌江, 白沙, 东方, 乐东) [徐龙辉等, 1983; 史 } \\
\text { 海 涛, 2001; 吴 毅 等, 2003] Qiongzhong, (Qionghai, } \\
\text { Changjiang, Baisha, Dongfang, Ledong) [Xu et al, 1983; Shi, } \\
\text { 2001; Wu et al, 2003] }\end{array}$ \\
\hline $\begin{array}{l}\text { 24. 普通伏翼 } \\
\text { Pipistrellus pipistrellus }\end{array}$ & 86 & 12 & $\mathrm{LC}$ & $\mathrm{Ea}$ & $\begin{array}{l}\text { 白沙, 保亭, 儋州, 陵水, 海口, 琼海, 琼中 Baisha, Baoting, } \\
\text { Danzhou, Lingshui, Haikou, Qionghai, Qiongzhong }\end{array}$ \\
\hline 25. 小伏翼 Pipistrellus tenuis & & $\sqrt{ }$ & NT & Wa & (地点不详) [蒋志刚等, 2015] (Unknown) [Jiang et al, 2015] \\
\hline $\begin{array}{l}\text { 26. 灰伏翼 } \\
\text { Hypssugo pulveratus }\end{array}$ & 4 & 1 & NT & $\mathrm{Sd}$ & $\begin{array}{l}\text { 陵水, (东方, 乐东) [寿振黄等, 1966; 徐龙辉等, 1983; 史海 } \\
\text { 涛, 2001; 王应祥, 2003; 吴毅等, 2003] Lingshui, (Dongfang, } \\
\text { Ledong) [Shaw et al, 1966; Xu et al, 1983; Shi, 2001; Wang, } \\
\text { 2003; Wu et al, 2003] }\end{array}$ \\
\hline
\end{tabular}


胡宜峰, 余文华, 岳阳, 黄正澜管, 李玉春, 吴毅. 海南岛翼手目物种多样性现状与分布预测. 生物多样性, 2019,27 (4): 400-408.

http://www.biodiversity-science.net/CN/10.17520/biods.2018256

\begin{tabular}{|c|c|c|c|}
\hline pecies & $\begin{array}{l}\text { 标本数量 } \\
\text { No. of } \\
\text { specimens }\end{array}$ & $\begin{array}{ll}\text { 文献记载 } & \text { 濒危等级 分布区系 } \\
\text { 数量 } & \text { IUCN-categDistribution } \\
\text { Recordation ories } & \end{array}$ & $\begin{array}{l}\text { 采集地 } \\
\text { Location }\end{array}$ \\
\hline
\end{tabular}

$\begin{array}{lllll}\begin{array}{l}\text { 27. 南蝠 Ia io } \\ \text { 28. 中华山蝠 Nyctalus plancyi }\end{array} & 5 & \mathrm{NT} & \mathrm{Si} \\ \begin{array}{l}\text { 29. 褐扁颅蝠 } \\ \begin{array}{l}\text { Tylonycteris robustula } \\ \text { 30. 斑蝠 Scotomanes ornatus }\end{array}\end{array} & 5 & 6 & \mathrm{LC} & \mathrm{Sv} \\ & 1 & \mathrm{LC} & \mathrm{Wb} \\ \text { 31. 大黄蝠 Scotophilus heathi } & 1 & 6 & \mathrm{LC} & \mathrm{Wb} \\ & & & & \\ \text { 32. 小黄蝠 Scotophilus kuhlii } & 81 & 196 & \mathrm{LC} & \mathrm{Wb}\end{array}$
(Lingshui) [Zhu et al, 2008a; Li et al, 2010]
(陵水) [朱光剑等, 2008b] (Lingshui) [Zhu et al, 2008b]

陵水，琼中 [余文华等, 2008; 张礼标等, 2008] Lingshui, Qiongzhong [Yu et al, 2008; Zhang et al, 2008]

(琼中, 五指山, 保亭, 陵水) [寿振黄等, 1966; 徐龙辉等, 1983; 史海涛, 2001] (Qiongzhong, Wuzhishan, Baoting, Lingshui) [Shaw et al, 1966; Xu et al, 1983; Shi, 2001]

陵水, (儋州, 东方, 乐东) [寿振黄等, 1966; 徐龙辉等, 1983; 史海涛, 2001] Lingshui, (Danzhou, Dongfang, Ledong) [Shaw et al, 1966; Xu et al, 1983; Shi, 2001]

海口, 陵水, 琼中, (文昌, 临高, 澄迈, 儋州, 定安, 乐东) [徐龙辉等, 1983; 史海涛, 2001; 王应祥, 2003; 李玉春等, 2006a; 朱斌良等, 2008; 李德伟等, 2010] Haikou, Lingshui, Qiongzhong, (Wenchang, Lingao, Chengmai, Danzhou, Dingan, Ledong) [Xu et al, 1983; Shi, 2001; Wang, 2003; Li et al, 2006a; Zhu et al, 2008; Li et al, 2010]

\author{
33. 圆耳管鼻蝠 \\ Murina cyclotis \\ 34. 艾氏管鼻蝠 Murina eleryi* 2 \\ 35. 哈氏管鼻蝠 \\ Murina harrisoni \\ 36. 毛翼管鼻蝠 1 \\ Harpiocephalus harpia \\ 37. 彩蝠 Kerivoula picta
}

38. 暗褐彩蝠 Kerivoula furva 2

\section{长翼蝠科 Miniopteridae}

39. 亚洲长翼蝠
Miniopterus fuliginosus

110

\begin{abstract}
40. 几内亚长翼蝠
Miniopterus magnater
\end{abstract}

41. 南长翼蝠

Miniopterus pusillus
2





2

2 EN Wc

$\begin{array}{ll}\text { NT } & \text { We } \\ \text { NT } & \text { We } \\ \text { DD } & \text { We } \\ \text { NT } & \text { Wc } \\ \text { EN } & \text { Wc }\end{array}$

琼中 [徐龙辉等, 1983; 史海涛, 2001; 王应祥, 2003] Qiongzhong [Xu et al, 1983; Shi, 2001; Wang, 2003]

琼中 Qiongzhong

乐东, 琼中 Ledong, Qiongzhong

琼中 [胡宜峰等, 2018] Qiongzhong [Hu et al, 2018]

陵水, (万宁, 三亚) [徐龙辉等, 1983; 史海涛, 2001; 王应祥, 2003; http://bbs.hainan.net/post-40-626081-1.shtml.] Lingshui, (Wanning, Sanya) [Xu et al, 1983; Shi, 2001; Wang, 2003; http://bbs.hainan.net/post-40-626081-1.shtml.]

NT We 陵水 [Wu et al, 2012; Yu et al, 2018] Lingshui [Wu et al, 2012; Yu et al, 2018]

保亭, 海口, 陵水, 琼中, (儋州, 昌江, 白沙, 东方) [寿振黄 等, 1966; 徐龙辉等, 1983; 朱斌良等, 2008; 李德伟等, 2010] Baoting, Haikou, Lingshui, Qiongzhong, (Danzhou, Changjiang, Baisha, Dongfang) [Shaw et al, 1966; Xu et al, 1983; Zhu et al, 2008; Li et al, 2010]

(海口) [李玉春等, 2006a] (Haikou) [Li et al, 2006a]

儋州, 海口, 陵水, 琼中, (昌江, 白沙, 东方, 乐东) [徐龙辉 等, 1983; 史海涛, 2001; 王应祥, 2003; 吴毅等, 2003; 李玉 春等, 2006a; 李德伟等, 2010] Danzhou, Haikou, Lingshui, Qiongzhong, (Changjiang, Baisha, Dongfang, Ledong) [Xu et al, 1983; Shi, 2001; Wang, 2003; Wu et al, 2003; Li et al, 2006a; Li et al, 2010]

(1) *: 海南岛分布新记录; (2) “、”: 有记录, 但无数量信息; (3) 濒危等级(蒋志刚等, 2016): LC: 无危; NT: 近危; VU: 易危; EN: 濒危; DD: 数据缺乏; (4) W: 东洋型(a: 热带; b: 热带-南亚热带; c: 热带-中亚热带; d: 热带-北亚热带; e: 热带-温带); S: 南中国型(c: 热带-中亚热带; i: 中亚热带; v: 热带-中温带); U: 古北型(h: 温带为主, 再延伸至热带); E: 季风型(a: 包括阿穆尔或再延展至俄罗斯远东地区); O: 不易归 类, 分布较广 (3: 地中海附近-中亚或东亚)(张荣祖, 1999); (5) “( )”: 括号内分布点是前人采集或记录到的分布点, 本研究组未采集到。

(1) *: New record of Hainan Island; (2) ' $\checkmark$ ': recorded, no quantitative information; (3) IUCN (Jiang et al, 2015): LC, least concern; NT, near threatened; VU, vulnerable; EN, endangered; DD, data deficient; (4) W: Oriental realm (a: tropic; b: tropical-south subtropical; c: tropical-middle subtropical; d: tropical-north subtropical; e: tropical-temperate); S: South China region (c: tropical-middle subtropical; i: middle subtropical; v: tropical-middle temperature); U: Palearctic realm (h: the temperate dominates and extends into tropics); E: Monsoon type (a: including Amur or extending to the far east in Russian); O: Difficult to categorize with wide distribution (3: near the Mediterranean-central or east Asia) (Zhang, 1999); (5) “( )": collection point of references. 
胡宜峰，余文华，岳阳，黄正澜懿，李玉春，吴毅. 海南岛翼手目物种多样性现状与分布预测. 生物多样性, 2019, 27 (4): 400-408. http://www.biodiversity-science.net/CN/10.17520/biods.2018256

附录3 不同地区的艾氏管鼻蝠及金管鼻蝠的外形及头骨测量

Appendix 3 The external, skull and mandibule measurements of Murina eleryi from different locations comparing with Murina aurata

\begin{tabular}{|c|c|c|c|c|c|c|c|c|}
\hline \multirow{3}{*}{ 项目 Items } & \multicolumn{7}{|c|}{$\begin{array}{c}\text { 艾氏管鼻蝠 } \\
\text { Murina eleryi }\end{array}$} & \multirow{3}{*}{$\begin{array}{c}\text { 金管鼻蝠 } \\
\text { Murina aurata } \\
\text { 四川, 模式标本 } \\
\text { Sichuan, Holotype } \\
\text { (Eger \& Lim, } 2011 \\
\text { O, } n=2 \\
\text { Mean }\end{array}$} \\
\hline & \multicolumn{2}{|c|}{$\begin{array}{c}\text { 海南琼中 } \\
\text { Qiongzhong, Hainan } \\
\text { 本研究 This study }\end{array}$} & \multicolumn{2}{|r|}{$\begin{array}{c}\text { 广东 } \\
\text { Guangdong } \\
\text { (Xu et al, 2014) } \\
\end{array}$} & \multirow{2}{*}{ 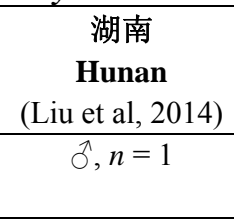 } & \multicolumn{2}{|c|}{$\begin{array}{c}\text { 越南 } \\
\text { Vietnam } \\
\text { (Furey et al, 2009) }\end{array}$} & \\
\hline & $\begin{array}{c}\hat{\partial}, n=1 \\
\text { GZHU16448 }\end{array}$ & $\begin{array}{c}\text { P, } n=1 \\
\text { GZHU16452 }\end{array}$ & $\hat{\sigma}, n=1$ & $\begin{array}{c}\text { P, } n=4 \\
\text { Mean } \pm \text { SD (Range) }\end{array}$ & & $\begin{array}{c}\delta, n=5 \\
\text { Mean } \pm \text { SD (Range) }\end{array}$ & $\begin{array}{c}\text { + }, n=6 \\
\text { Mean } \pm \text { SD (Range) }\end{array}$ & \\
\hline 体重(Wt, g) & 3.9 & 4.4 & 3.5 & $3.6(3.3-3.9)$ & & $4.4(4.0-5.0)$ & $4.7 \pm 0.7(4.0-5.5)$ & \\
\hline 前臂长 $(\mathrm{FA}, \mathrm{mm})$ & 28.3 & 30.59 & 27.79 & $30.79 \pm 0.85(30.20-32.00)$ & 26.3 & $28.3 \pm 0.7(27.7-29.4)$ & $29.9 \pm 1.0(28.6-31.3)$ & 29.14 \\
\hline 尾长 $(\mathrm{T}, \mathrm{mm})$ & 30.28 & 31.06 & 32.74 & $30.73 \pm 2.65(27.88-34.25)$ & 24.5 & $29.5 \pm 1.5(27.3-31.7)$ & $29.5 \pm 1.5(27.3-31.7)$ & \\
\hline 后足长(HF, mm) & 7.14 & 7.31 & 6.32 & $7.35 \pm 0.84(12.18-14.00)$ & 6.2 & $6.6 \pm 0.8(5.6-7.7)$ & $6.7 \pm 0.6(6.0-7.4)$ & \\
\hline 胫骨长(Tib, mm) & 14.46 & 15.42 & 14.03 & $13.17 \pm 1.10(12.58-14.88)$ & 13 & $14.0 \pm 0.7(13.0-14.7)$ & $13.6 \pm 0.7(12.8-14.8)$ & 12 \\
\hline 耳长 $(\mathrm{E}, \mathrm{mm})$ & 11.23 & 12.84 & 12.91 & $13.26 \pm 0.84(12.18-14.00)$ & 9.9 & $12.3 \pm 0.7(11.5-12.6)$ & $12.7 \pm 0.8(12.0-13.3)$ & \\
\hline 颅全长(GTL, mm) & 15.22 & 15.61 & 14.51 & $15.42 \pm 0.24(15.11-15.68)$ & 14.4 & $14.64(14.18-14.94)$ & $15.01 \pm 0.29(14.62-15.33)$ & 14.2 \\
\hline 枕犬长(CCL, mm) & 12.99 & 13.67 & 12.75 & $13.26 \pm 0.06(13.21-13.32)$ & 12.5 & $12.36(12.14-12.59)$ & $12.66 \pm 0.24(12.43-12.99)$ & \\
\hline 歡宽 $(\mathrm{ZW}, \mathrm{mm})$ & 8.43 & 8.6 & 8.16 & $8.28 \pm 0.15(8.07-8.40)$ & 7.5 & $8.03 \pm 0.15(7.84-8.22)$ & $8.16 \pm 0.11(8.09-8.36)$ & 7.59 \\
\hline 眶间宽(IOW, mm) & 4.17 & 4.28 & 4.1 & $4.09 \pm 0.12(3.96-4.25)$ & 4.1 & $4.28 \pm 0.11(4.18-4.46)$ & $4.17 \pm 0.10(4.01-4.28)$ & 4.17 \\
\hline 脑频高(BCH, mm) & 5.71 & 5.93 & 5.82 & $6.75 \pm 0.72(5.79-7.37)$ & 5.6 & $5.67 \pm 0.12(5.49-5.77)$ & $5.57 \pm 0.12(5.44-5.78)$ & \\
\hline 腭长(PL, mm) & 6.2 & 6.23 & 6.29 & $6.27 \pm 0.19(6.07-6.53)$ & & & & 6.02 \\
\hline 上齿列长 $\left(\mathrm{C}^{1}-\mathrm{M}^{3}, \mathrm{~mm}\right)$ & 4.71 & 5.91 & 4.61 & $4.91 \pm 0.15(4.77-5.12)$ & 4.7 & $4.60(4.50-4.70)$ & $4.68 \pm 0.09(4.61-4.82)$ & 4.27 \\
\hline 上犬齿宽 $\left(C^{1}-C^{1}, m m\right)$ & 3.7 & 3.72 & 3.46 & $3.72 \pm 0.09(3.59-3.78)$ & 3.4 & $3.43(3.21-3.62)$ & $3.55(3.49-3.63)$ & 3.18 \\
\hline 上兒齿宽 $\left(\mathrm{M}^{3}-\mathrm{M}^{3}, \mathrm{~mm}\right)$ & 5.2 & 5.35 & 4.97 & $5.42 \pm 0.30(4.98-5.62)$ & 5.4 & $4.92 \pm 0.23(4.62-5.19)$ & $5.01 \pm 0.13(4.87-5.18)$ & \\
\hline 上犬齿前臼齿长 $\left(\mathrm{CP}^{4} \mathrm{~L}, \mathrm{~mm}\right)$ & 2.26 & 2.34 & & & & $2.08(2.05-2.11)$ & $2.15 \pm 0.05(2.08-2.22)$ & \\
\hline 下齿列长 $\left(\mathrm{C}_{1}-\mathrm{M}_{3}, \mathrm{~mm}\right)$ & 5.39 & 5.7 & 5.12 & $4.82 \pm 0.89(3.49-5.44)$ & 5.1 & $5.11 \pm 0.17(4.89-5.33)$ & $5.19 \pm 0.08(5.10-5.32)$ & 4.46 \\
\hline 下犬齿前臼齿长 $\left(\mathrm{CP}_{4} \mathrm{~L}, \mathrm{~mm}\right)$ & 1.94 & 2.05 & & & & $1.87 \pm 0.06(1.82-1.96)$ & $1.92 \pm 0.09(1.77-2.00)$ & \\
\hline 下领长(ML, mm) & 9.6 & 10.01 & 9.25 & $9.66 \pm 0.08(9.59-9.76)$ & 9.6 & $9.46 \pm 0.14(9.29-9.60)$ & $9.57 \pm 0.25(9.33-9.97)$ & 8.59 \\
\hline 下领高(MH, mm) & 3.27 & 3.42 & 3.39 & $3.18 \pm 0.05(3.11-3.22)$ & & $2.92 \pm 0.14(2.80-3.15)$ & $3.03 \pm 0.12(2.88-3.23)$ & 2.87 \\
\hline
\end{tabular}

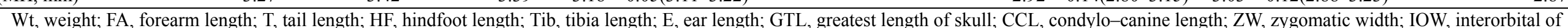

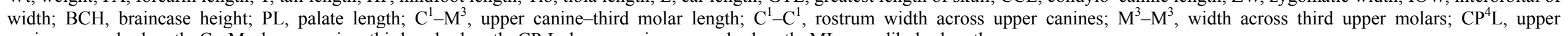
canine-premolar length; $\mathrm{C}_{1}-\mathrm{M}_{3}$, lower canine-third molar length; $\mathrm{CP}_{4} \mathrm{~L}$, lower canine-premolar length; ML, mandibular length. 
胡宜峰, 余文华, 岳阳, 黄正澜懿, 李玉春, 吴毅. 海南岛翼手目物种多样性现状与分布预测. 生物多样性, 2019, 27 (4): 400-408.

http://www.biodiversity-science.net/CN/10.17520/biods.2018256

参考文献

Eger JL, Lim BK (2011) Three new species of Murina from Southern China (Chiroptera: Vespertilionidae). Acta

Chiropterologica, 13, 227-243.

Furey NM, Thong VD, Bates PJJ, Csorba G (2009) Description of a new species belonging to the Murina

'suilla-group' (Chiroptera: Vespertilionidae: Murininae) from North Vietnam. Acta Chiropterologica, 11, $225-236$.

Hu YF, Li F, Wu Y, Li YC, Yu WH (2018) New record of Harpiocephalus harpia in Hainan Province. Journal of

Zhejiang Forestry Science and Technology, 38(3), 85-88. (in Chinese with English abstract) [胡宜峰, 黎舫, 吴毅, 李玉春, 余文华 (2018) 海南省蝙蝠新记录——毛翼管鼻蝠. 浙江林业科技, 38(3), 85-88.]

Jiang ZG, Jiang JP, Wang YZ, Zhang E, Zhang YY, Li LL, Xie F, Cai B, Cao L, Zheng GM, Dong L, Zhang ZW, Ding P, Luo ZH, Ding CQ, Ma ZJ, Tang SH, Cao WX, Li CW, Hu HJ, Ma Y, Wu Y, Wang YX, Zhou KY, Liu SY, Chen YY, Li JT, Feng ZJ, Wang Y, Wang B, Li C, Song XL, Cai L, Zang CX, Zeng Y, Meng ZB, Fang HX, Ping XG (2016) Red List of China's Vertebrates. Biodiversity Science, 24, 500-551. (in Chinese and in English) [蒋志刚, 江建平, 王跃招, 张鹗, 张雁云, 李立立, 谢锋, 蔡波, 曹亮, 郑光美, 董路, 张正旺, 丁 平, 罗振华, 丁长青, 马志军, 汤宋华, 曹文宣, 李春旺, 胡慧建, 马勇, 吴毅, 王应祥, 周开亚, 刘少英, 陈跃英, 李家堂, 冯祚建, 王燕, 王斌, 李成, 宋雪琳, 蔡蕾, 藏春金鐸, 岩, 孟智斌, 方红霞, 平晓鸽 (2016) 中国脊椎动物红色名录. 生物多样性, 24, 500-551.]

Jiang ZG, Ma Y, Wu Y, Wang YX, Zhou KY, Liu SY, Feng ZJ, Li LL (2015) China's Mammal Diversity and Geographic Distribution. Science Press, Beijing. (in Chinese with English abstract) [蒋志刚, 马勇, 吴毅, 王 应祥, 周开亚, 刘少英, 冯祚建, 李立立 (2015) 中国哺乳动物多样性及地理分布. 科学出版社, 北京.]

Li DW, Yin F, Zeng Y, Zhang Y, Zhang XW (2010) Cluster analysis on the distribution patterns of Chiroptera in Hainan Island. Journal of Biology, 27(2), 16-20. (in Chinese with English abstract) [李德伟, 尹锋, 曾玉, 张 园, 张信文 (2010) 海南岛翼手类地理分布格局的聚类分析. 生物学杂志, 27(2), 16-20.]

Li YC, Chen Z, Long YR, Zhou F, Zhong YR (2006a) Species diversity of Chiroptera in Ma'anling Volcano Area, Hainan Island. Chinese Journal of Zoology, 41, 106-109. (in Chinese with English abstract) [李玉春, 陈忠, 龙 育儒, 周锋, 钟友仁 (2006a) 海南岛马鞍岭火山口地区翼手目物种多样性. 动物学杂志, 41, 106-109.]

Li YC, Wu Y, Chen Z (2006b) A new record of Rickett's big-footed bat Myotis ricketti in Hainan Island of China. Acta Theriologica Sinica, 26, 211-212. (in Chinese with English abstract) [李玉春, 吴毅, 陈忠 (2006b) 海南 岛发现大足鼠耳蝠分布新纪录. 兽类学报, 26, 211-212.]

Liu ZX, Zhang YX, Zhang JS, Zhang LB (2014) Murina eleryi discovered in Hunan Province. Chinese Journal of Zoology, 49, 132-135. (in Chinese with English abstract) [刘志霄, 张佑祥, 张劲硕, 张礼标 (2014) 湖南 省发现艾氏管鼻蝠. 动物学杂志, 49, 132-135.]

Shaw TH, Wang S, Lu CK, Chang LK (1966) A survey of the mammals of Hainan Island, China. Acta Zootaxonomica Sinica, 3, 260-276. (in Chinese with English abstract) [寿振黄, 汪松, 陆长坤, 张鑾光 (1966) 海南岛的兽类调查. 动物分类学报, 3, 260-276.]

Shi HT (2001) Retrieval of Terrestrial Vertebrates in Hainan. Hainan Publishing House, Haikou. (in Chinese) [史 海涛 (2001) 海南陆栖脊椎动物检索. 海南出版社, 海口.]

Wang YX (2003) A Complete Checklist of Mammal Species and Subspecies in China: A Taxonomic and Geographic Reference. China Forestry Publishing House, Beijing. (in Chinese with English abstract) [王应祥 (2003) 中国哺乳动物物种与亚种分类名录与分布大全. 中国林业出版社, 北京.]

Wu Y, Li YC, Lin LK, Harada M, Chen Z, Motokawa M (2012) New records of Kerivoula titania (Chiroptera: 
胡宜峰, 余文华, 岳阳, 黄正澜懿, 李玉春, 吴毅. 海南岛翼手目物种多样性现状与分布预测. 生物多样性, 2019, 27 (4): 400-408.

http://www.biodiversity-science.net/CN/10.17520/biods.2018256

Vespertilionidae) from Hainan Island and Taiwan. Mammal Study, 37, 69-72.

Wu Y, Jiang HS, Peng HY, Li SN, Wang WY (2003) Study on the species biodiversity of mammals in Diaoluoshan Mountain. Journal of Guangzhou University (Natural Science Edition), 2, 505-511. (in Chinese with English abstract) [吴毅, 江海声, 彭洪元, 李仕宁, 王文毅 (2003) 吊罗山保护区哺乳动物多样性初 步研究. 广州大学学报(自然科学版), 2, 505-511.]

Xu L H, Liu ZH, Yu SM (1983) Birds and Beasts of Hainan Island, China. Science Press, Beijing. (in Chinese) [徐 龙辉, 刘振河, 余斯绵 (1983) 海南岛的鸟兽. 科学出版社, 北京.]

Xu ZX, Yu WH, Wu Y, Li F, Chen BC, Harada M, Motokawa M, Gong YN, Li YC (2014) Preliminary study on population genetic structure and taxonomy of Elery's tube-nosed bat (Murina eleryi). Acta Theriologica Sinica, 34, 270-277. (in Chinese with English abstract) [徐忠鲜, 余文华, 吴毅, 李锋, 陈柏承, 原田正史, 本川雅治, 龚粤宁, 李玉春 (2014) 艾氏管鼻蝠种群遗传结构初步研究及其分类探讨. 兽类学报, 34, 270-277.]

Yu WH, Wu Y, Li YC, Jiang HS, Chen Z (2008) A new record of greater bamboo bat Tylonycteris robustula of Hainan Island. Journal of Guangzhou University (Natural Science Edition), 7, 30-33. (in Chinese with English abstract) [余文华, 吴毅, 李玉春, 江海声, 陈忠 (2008) 海南岛发现褐扁乑蝠(Tylonycteris robustula)分布 新纪录. 广州大学学报(自然科学版), 7, 30-33.]

Yu WH, Li F, Csorba G, Xu ZX, Wang XY, Guo WJ, Li YC, Wu Y (2018) A revision of Kerivoula hardwickii and occurrence of $K$. furva (Chiroptera: Vespertilionidae) in China. Zootaxa, 4461, 45-56.

Zhang LB, Zhu GJ, Yu DM, Ye JP, Zhang W, Hong TY, Tan M (2008) New record of Tylonycteris robustula (Chiroptera: Vespertilionidae) from Hainan, Guizhou, and Sichuan Province. Acta Theriologica Sinica, 28, 316-320. (in Chinese with English abstract) [张礼标, 朱光剑, 于冬梅, 叶建平, 张伟, 洪体玉, 谭敏 (2008) 海南、贵州和四川三省翼手类新纪录——褐扁顽蝠. 兽类学报, 28, 316-320.]

Zhang RZ (1999) Zoogeography of China. Science Press, Beijing. (in Chinese) [张荣祖 (1999) 中国动物地理. 科学出版社, 北京.]

Zhu BL, Zhu GJ, Li DW, Hong TY, Zhang XW (2008) A preliminary survey on species diversity of Chiroptera in Hainan Island. Journal of Hainan Normal University (Natural Science), 21(1), 75-81. (in Chinese with English abstract) [朱斌良, 朱光剑, 李德伟, 洪体玉, 张信文 (2008) 海南岛翼手目物种多样性的初步调查. 海南 师范大学学报(自然科学版), 21, 75-81.]

Zhu GJ, Li DW, Ye JP, Hong TY, Zhang LB (2008a) New record of Ia io in Hainan Island, its echolocation pulses and ND1 analysis. Chinese Journal of Zoology, 43, 69-75. (in Chinese with English abstract) [朱光剑, 李德伟, 叶建平, 洪体玉, 张礼标 (2008a) 南蝠海南岛分布新纪录、回声定位信号和ND1分析. 动物学杂志, 43, 69-75.]

Zhu GJ, Han NJ, Hong TY, Tan M, Yu DM, Zhang LB (2008b) Echolocation call, roost and ND1 sequence analysis of new record of Nyctalus plancyi (Chiroptera: Vespertilionidae) on Hainan Island. Zoological Research, 29, 447-451. (in Chinese with English abstract) [朱光剑, 韩乃坚, 洪体玉, 谭敏, 于冬梅, 张礼标 (2008b) 海南属种新纪录——中华山蝠的回声定位信号、栖息地及序列分析. 动物学研究, 29, 447-451.] 